\title{
The Future of Synthetic Carbohydrate Vaccines: Immunological Studies on Streptococcus pneumoniae Type 14
}

\author{
Dodi Safari, Ger Rijkers and Harm Snippe \\ Additional information is available at the end of the chapter
}

http://dx.doi.org/10.5772/48326

\section{Introduction}

Studies on synthetic carbohydrates to be used as potential vaccine candidates for polysaccharide encapsulated bacteria were started in the mid-1970s. They were the logical follow-up to studies being performed at that time on the immunogenicity of antigens composed of carrier proteins and synthetic hapten groups. Hapten-carrier complexes were first introduced in immunology by Karl Landsteiner in the early 1900s [1]. He discovered that (i) small organic molecules with a simple structure, such as phenyl arsonates and nitrophenyls, do not provoke antibodies by themselves, but (ii) if those molecules are attached covalently, by simple chemical reactions, to a protein carrier, then antibodies against those small organic molecules are evoked. Since their introduction, these haptencarrier complexes have become excellent tools to elucidate the role of different antigenreactive cells in the immune response [2]. The key players in this immunological process are thymus-derived $\mathrm{T}$ cells and bone marrow-derived B cells. The former group of lymphoid cells is responsible for various phenomena of cell-mediated immunity, e.g. delayed hypersensitivity, allograft-, and graft-versus-host reactions, and reacts with specific determinants on the carrier protein ( $\mathrm{T}$ cell epitopes). The latter group of lymphoid cells (B cells) give rise to the precursors of antibody-secreting cells, and reacts with both the carrier protein and the synthetic haptenic determinants. This results in antibody formation to both the carrier and the hapten.

The reason to apply the above concepts and techniques to carbohydrate antigens was to address an immunological problem: polysaccharide molecules are classified as so-called thymus-independent (TI) antigens, because they do not require T cells to induce an immune response of B cells. As a result, the antibodies formed are mainly of the IgM class and have a 
low avidity. Moreover, no immunological memory is generated and the antigens are poorly immunogenic in infants. Latter characteristic has major implications for development of vaccines against polysaccharide encapsulated bacteria. It was hypothesized that by linking small carbohydrates (oligosaccharides) to a carrier protein, the immunogenic behavior would change to that of a thymus-dependent (TD) antigen. Therefore, the studies of both Goebel [3, 4] and Campbell and Pappenheimer [5], who first isolated the antigenic determinant of Streptococcus pneumoniae type 3, were combined and extended. The hapteninhibition studies by Mage and Kabat [6] demonstrated that the antibody-combining site of type 3 pneumococcal polysaccharide consists of two to three cellobiuronic acid units. In the dextran-anti-dextran system extensively studied by Kabat and colleagues [7] the upper size limit of the antibody-combining site appeared to be a hexa- or heptasaccharide and the lower limit was estimated to be somewhat larger than a monosaccharide. Snippe and colleagues [8] proved in 1983 that small synthetic oligosaccharides (tetra- and hexasaccharides) of $S$. pneumoniae type 3 could be transformed into TD antigens by conjugating them to a protein carrier. This opened the way to explore the synthesis and immunogenicity of numerous oligosaccharide-carrier protein conjugates of different pneumococcal serotypes. Those studies culminated in 2004 in the large-scale synthesis and introduction of a synthetic oligosaccharide vaccine for Haemophilus influenzae type b for use in humans in Cuba [9]. The recent exploration of gold nanoclusters coated with synthetic oligosaccharides and peptides as a vaccine are a promising platform towards the development of fully synthetic carbohydrate-based vaccines [10].

\section{Streptococcus pneumoniae}

Streptococcus pneumoniae (S. pneumoniae or pneumococcus) is a leading cause of bacterial pneumonia, meningitis, and sepsis in children worldwide. It is estimated that 1.6 million people die from these infections each year, of whom one million are children [11, 12]. $S$. pneumoniae are lancet-shaped, gram-positive, and alpha-hemolytic bacteria that colonize the mucosal surfaces of the upper respiratory tract [13]. Three major surface layers can be distinguished from the inside to the outside: the plasma membrane, the cell wall, and the capsule (Fig. 1) [14]. The cell wall consists of a triple-layered peptidoglycan backbone that anchors the capsular polysaccharide, the cell wall polysaccharide, and also various proteins such as pneumococcal surface protein A (pspA) and hyluronate lyase (Hyl) (Fig. 1). The capsule is the thickest layer, completely concealing the inner structures of exponentially growing S. pneumoniae bacteria.

\section{Capsular polysaccharide}

Capsular polysaccharides are well known as the major virulence factors of S. pneumoniae. Today more than 92 serotypes have been identified based on the different chemical structures of these polysaccharides [16, 17]. This diversity determines the ability of the serotypes to survive in the bloodstream and very likely the ability to cause invasive disease, especially in 
the respiratory tract $[14,16]$. Recently, new S. pneumoniae serotypes have been identified, e.g. serotype 6C [17], 6D [18, 19], and 11E [20]. Capsular polysaccharides are large polymers (0.5$\left.2 \times 10^{6} \mathrm{Da}\right)$, composed of multiple repeating units of up to eight sugar residues [14]. The capsular polysaccharides are generally synthesized by the Wzx/Wzy-dependent pathway, except for type 3 and 37 which are synthesized by the synthase pathway [21, 22] (Fig. 2). In the synthase pathway capsule is produced through processive transferase activity [23, 24].

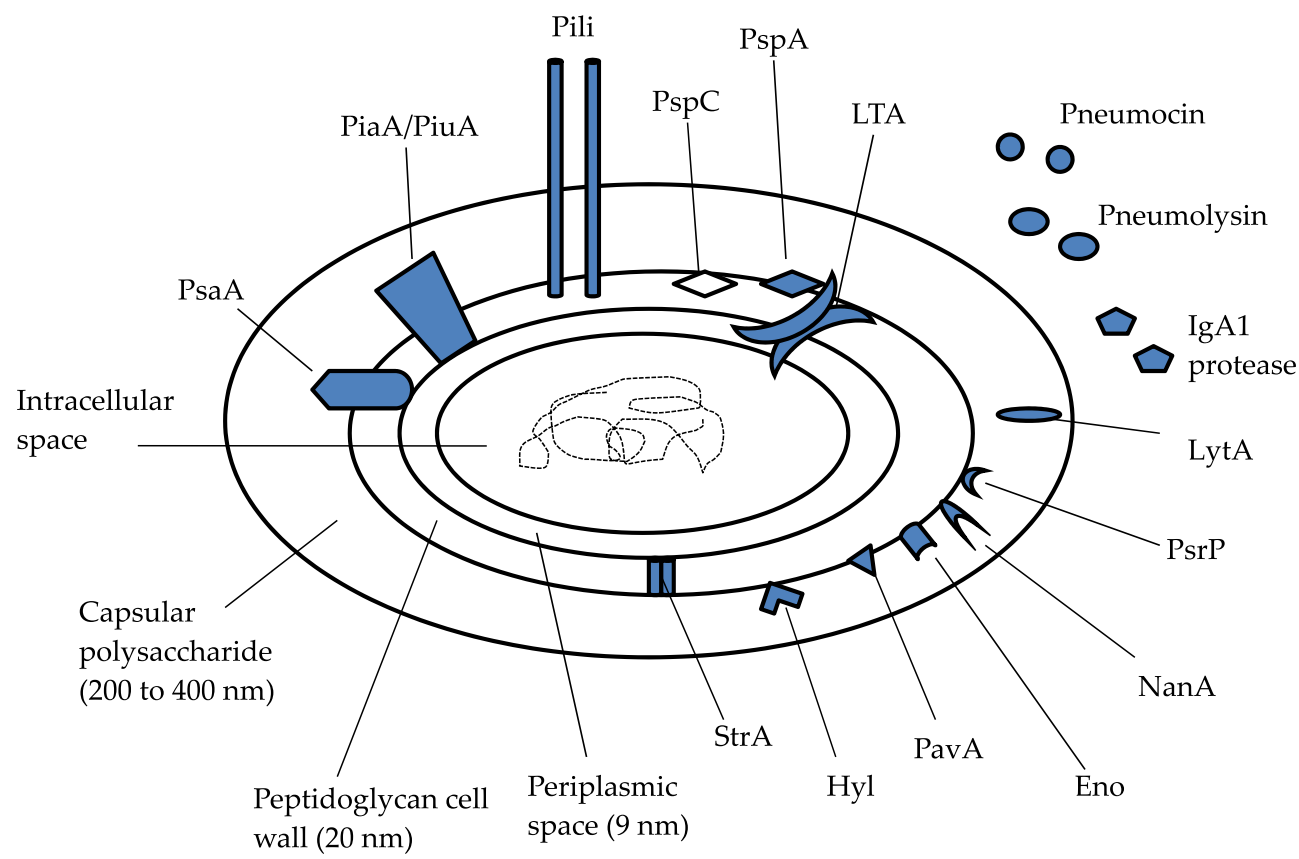

Figure 1. Schematic structure of $S$. pneumoniae. StrA=sortase A. Hyl=hyluronate lyase.

PavA=pneumococcal adhesion and virulence. Eno=enolase. $\mathrm{Nan} A=$ neuraminidase. $\mathrm{PsrP}=$ pneumococcal serine-rich repeat protein. LytA=autolysin. $\mathrm{LTA}=$ lipoteichoic acid. PspA=pneumococcal surface protein A. PspC=pneumococcal surface protein $\mathrm{C}$. PiaA/PiuA=pneumococcal iron acquisition and uptake. PsaA=pneumococcal surface antigen A. (Adopted from van der Poll, T. and Opal, S.M. [15] and de Velasco, E.A. et al [14])

Many studies have demonstrated that antibodies directed against the capsular polysaccharide are essential for protection against pneumococcal disease [25-27]. However, the native capsular polysaccharides are well-known thymus-independent type-2 (TI-2) antigens that lack T-helper epitopes and therefore mainly induce IgM antibodies, and to a lesser degree IgG [28]. The TI-2 characteristics of polysaccharides can be altered by conjugation of polysaccharide to a protein carrier (glycoconjugate) resulting in a switch to an anti-polysaccharide antibody response with characteristics of a T-cell-dependent response. This is reflected by the generation of memory $\mathrm{B}$ and $\mathrm{T}$ cells and the induction of high titers of anti-polysccharide IgG antibodies after booster immunization [29]. 
It should be noted that not all polysaccharides behave as TI-2 antigens. Zwitterionic polysaccharides such as $S$. pneumoniea type 1 polysaccharide: $[\rightarrow 3)-\alpha$-AATGal-( $1 \rightarrow 4)-\alpha$-DGalpA-(1 $\rightarrow 3)-\alpha-D-G a l p A-(1 \rightarrow]_{n}$ with a right-handed helix with repeated zwitterionically charged grooves elicit potent $\mathrm{T}$ cell responses in vivo and in vitro [30, 31].

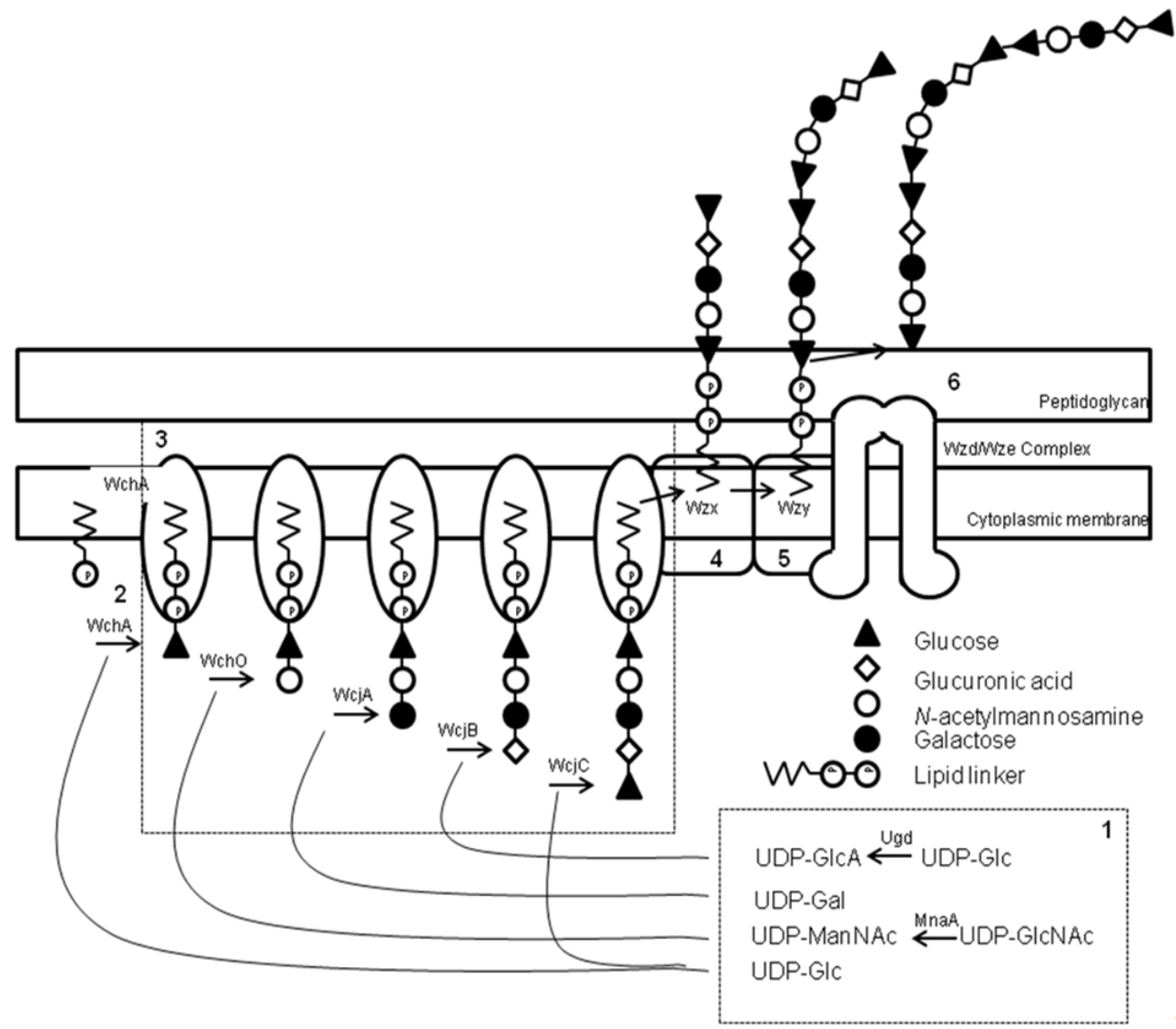

Figure 2. Representation of the Wzx/Wzy-dependent pathway for biosynthesis of CPS 9A (Adopted from Bentley. S.D. et al [21]). Representation of the Wzx/Wzy-Dependent Pathway Pictured is a hypothetical model for capsule biosynthesis in S. pneumoniae based on a mixture of experimental evidence and speculation.

1. Non-housekeeping nucleotide sugar biosynthesis.

2. The initial transferase (WchA in this case) links the initial sugar as a sugar phosphate (Glc-P) to a membrane-associated lipid carrier (widely assumed to be undecaprenyl phosphate).

3. Glycosyl transferases sequentially link further sugars to generate repeat unit.

4. Wzx flippase transports the repeat unit across the cytoplasmic membrane.

5. Wzy polymerase links individual repeat units to form lipid-linked CPS. 
6. Wzd/Wze complex translocates mature CPS to the cell surface and may be responsible for the attachment to peptidoglycan.

\section{Development of pneumococcal vaccines}

Although the first pneumococcal vaccines, including the application of the principle of conjugate vaccination, were already initiated in the beginning of the previous century, most of these developments stopped when antibiotics were introduced. Existing vaccines were even withdrawn from the market. By now, in many parts of the world, the antibiotic resistance of S. pneumoniae bacteria has increased: America [32, 33], Africa [34], Europe [35, 36], Asia [37-39], and Australia [40]. This makes treatment of pneumococcal infections more difficult and stresses the importance of the development of effective vaccines as a strategy to reduce morbidity and mortality caused by $S$. pneumoniae infection worldwide.

\subsection{Pneumococcal polysaccharide-based vaccines.}

Currently two vaccine types against $S$. pneumoniae are commercially available: a pneumococcal polysaccharide vaccine (PPV) and a pneumococcal conjugate vaccine (PCV) [41]. The first multivalent pneumococcal polysaccharide vaccine (PPV) contains 23 purified capsular polysaccharides (25 $\mu \mathrm{g}$ of each capsule type; Pneumovax ${ }^{\circledR}$, PPV23: 1, 2, 3, 4, 5, 6B, 7 , $8,9 \mathrm{~N}, 9 \mathrm{~V}, 10 \mathrm{~A}, 11 \mathrm{~A}, 12 \mathrm{~F}, 14,15 \mathrm{~B}, 15 \mathrm{~F}, 18 \mathrm{C}, 19 \mathrm{~A}, 19 \mathrm{~F}, 20,22 \mathrm{~F}, 23 \mathrm{~F}, 33 \mathrm{~F}$ ) which is licensed for use in adults and children older than 2 years of age [42]. This vaccine was shown to be moderately effective in young adults [43] but not in young children [44] and elderly [45] and also not in immunocompromised patients, e.g HIV infected people [46, 47].

In early 2000, a polysaccharide-protein conjugate vaccine targeting seven pneumococcal serotypes was licensed in the United States for use in young children (Prevnar ${ }^{\circledR}$, PCV7: 4, 6B, $9 \mathrm{~V}, 14,18 \mathrm{C}, 19 \mathrm{~F}, 23 \mathrm{~F})$. The polysaccharides are conjugated to the non-toxic cross reactive material from diphtheria toxin, $\mathrm{CRM}_{197}$ and each dose contains $2 \mu \mathrm{g}$ of each capsule type, except for $6 \mathrm{~B}$, for which $4 \mu \mathrm{g}$ is included in every vaccine dose[48]. The PCV7 vaccine produces a significant effect regarding prevention of invasive pneumococcal disease in children younger than 24 months (based on a meta-analysis of published data from trials on pneumococcal vaccine) [49]. Large scale introduction of PCV7 has resulted in an overall decline in infectious pneumococcal disease (IPD). However, IPD caused by the non-vaccine serotypes serotypes 1, 19A, 3, 6A, and 7F has increased (replacement disease), highlighting the need for inclusion of these serotypes in future improved vaccine formulations [50]. Apart from the CRM197 based PCV7, several new candidate pneumococcal conjugate vaccines have been developed to cover more serotypes with different protein carriers and most of them are in clinical trials, such as PCV10 vaccine $(1,4,5,6 \mathrm{~B}, 7 \mathrm{~F}, 9 \mathrm{~V}, 14,18 \mathrm{C}, 19 \mathrm{~F}$, 23F) [51, 52] and PCV13 vaccine (1, 3, 4, 5, 6A, 6B, 7F, 9V, 14, 18C, 19A, 19F, 23F) [53].

\subsection{Pneumococcal protein-based vaccines}

An alternative vaccine strategy focuses on the use of pneumococcal surface-associated proteins which are to be assumed to elicit protection in all age groups against all, or nearly 
all, pneumococcal serotypes (Fig. 1). Protection induced by the proteins should be serotypeindependent and possibly cheaper and thus within reach of developing countries [54]. Currently, several surface pneumococcal proteins are investigated as a candidate vaccine against $S$. pneumoniae infection with single or combination of recombinant proteins, such as pspA family fusion protein [55]; pneumolysis and pspA1/pspA2 combined [56]. Recently new candidate protein antigens were discussed at the $8^{\text {th }}$ International Symposium on Pneumococci and Pneumococcal Diseases at Iguaçu Falls, Brazil (2012), phtD (pneumococcal histidin triad protein D) and PcpA (pneumococcal choline binding protein A) [57].

\subsection{Pneumococcal synthetic oligosaccharide-based vaccines}

The current polysaccharide conjugate vaccines are based on natural polysaccharides, purified form bacterial cultures. Synthetic oligosaccharide-protein conjugates (neoglycoconjugate), involving functional mimics of the natural polysaccharide antigens have emerged as an attractive option [58]. The advantages of neoglycoconjugates are well-defined chemical structures (chain length, epitope conformation, and carbohydrate/protein ratio) as well as a lack of the impurities present in polysaccharides obtained from bacterial cultures $[59,60]$.

The chemical synthesis of oligosaccharide fragments however is complex. According to the sequence in the natural polysaccharide, monosaccharide residues have to be linked in such a way that they form an oligosaccharide with the required stereospecificity (epitope). Various methodologies and strategies for synthesis of carbohydrates have successfully been used for production of experimental neoglycoconjugates, as reviewed by Kamerling [16]. In 2001, the first automated synthesis of oligosaccharides was reported by Plante, O.J. et al [61].

Neoglycoconjugates have been prepared for saccharides of different microorganisms. In 2004, Verez Bencomo et al., reported the large-scale synthesis and the introduction of a synthetic oligosaccharide vaccine for Haemophilus influenzae type b for use in humans in Cuba [9]. The immunogenicity of the synthetic oligosaccharide fragment of the O-specific polysaccharide (O-PS) of Vibrio cholera O1, serotype Ogawa, conjugated to bovine serum albumin has been investigated in a mouse model $[62,63]$. A multimeric bivalent synthetic hexasaccharide fragment of the O-specific polysaccharide of Vibrio cholera O1, serotype Ogawa, in combination with Inaba: 1 or a synthetic disaccharide tetrapeptide peptidoglycan fragment as adjuvant were prepared and conjugated to recombinant tetanus toxin $\mathrm{H}(\mathrm{C})$ fragment as protein carrier [64]. The immunogenicity of synthetic oligosaccharides mimicking the Oantigen of the Shigella flexneri 2a lipopolysaccharide (LPS) was also investigated in mice [65, 66]. Immunization of mice with synthetic hexasaccharide of glycosylphosphatidylinositol malarial toxin conjugated to a protein carrier was reported to protect the mice from an otherwise lethal dose of malaria parasites [67]. A fully synthetic carbohydrate-based antitumor candidate vaccine for the common T-synthase was recently reported [68].

Meanwhile we and other groups have been working on improving the immunogenicity of neoglycoconjugates against different S. pneumoniae serotypes in animal models: Di-, tri-, and tetrasaccharides related to polysaccharide type 17F conjugated to keyhole limpet hemocyanin (KLH) protein[69, 70] and tri- and tetrasaccharides related to type 23 
conjugated to KLH protein [71]; Di-, tri-, and tetrasaccharides related to type 6B conjugated to KLH protein [72]; Di-, tri-, and tetrasaccharide related to type 3 conjugated to the crossreactive material of diphteria toxin $\left(\mathrm{CRM}_{197}\right)$ protein [60] and most recently overlapping oligosaccharide varying from tri- to dodecasaccharides related to polysaccharide type 14 conjugated to CRM197 protein [73, 74].

\section{Immunogenicity of synthetic oligosaccharide based vaccines}

This review focuses on the S. pneumoniae type 14 capsular polysaccharide (Pn14PS) which consists of biosynthetic repeating units of the tetrasaccharide $\{6)-[\beta-D-G a l p-(1 \rightarrow 4)-] \beta-D-$ GlcpNAc- $(1 \rightarrow 3)-\beta-D-G a l p-(1 \rightarrow 4)-\beta-D-G l c p-(1 \rightarrow\}$ n [75] (Fig. 3).

A

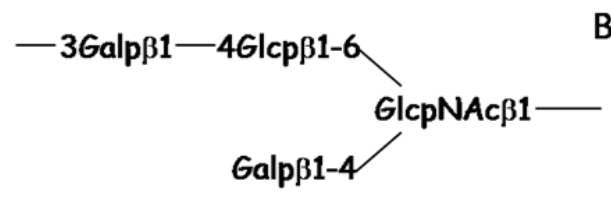

B

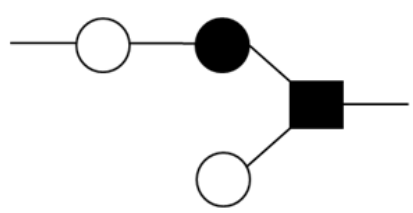

Figure 3. A branched tetrasaccharide repeating unit of $S$. pneumoniae type 14 capsular polysaccharide (A) and its nomenclature symbol (B): filled circle = glucose (Glc); open circle = galactose (Gal), and filled square $=\mathrm{N}$-acetylglucosamine $(\mathrm{GlcNAc})$

\subsection{Identification of the minimal structure of oligosaccharide capable in evoking anti-Pn14PS antibodies.}

It was reported that a synthetic branched tetrasaccharide, corresponding to a single structural repeating unit of Pn14PS conjugated to the cross-reactive material of diptheria toxin (CRM197), was found to induce anti-polysaccharide type 14 antibodies by Mawas, F. et al [74]. We continued to investigate further how small the minimal structure in Pn14PS can be and still produce specific antibodies against native polysaccharide type 14 [73]. 16 overlapping oligosaccharide fragments of Pn14PS were synthesized as described previously [76-79] and were conjugated to the protein carrier CRM ${ }_{197}$. The mice immunization studies were performed to investigate the immunogenicity of the neoglycoconjugates. We found that the fragments with a linear and/or incomplete branched structure did not elicit specific antibodies against native Pn14PS (Fig. 4: JJ118, JJ42, JJ141, DM65, JJ153, JJ9, JJ6 and DM35) [73]. High titer of anti-Pn14PS IgG antibodies was observed when the complete branched structure fragments, conjugated to the protein carrier were used in the mouse model (Fig. 4: JJ1, DM66, DM36, ML1, ML2, and CRM197-Pn14PS as a positive control), excepted for JJ5 and JJ10 which elicited low titer of anti-Pn14PS antibodies.

We also tested the phagocytic capacity of mice sera by human polymorph nuclear cells and a mouse macrophage cell line. We found that the sera containing antibodies against Pn14PS were also capable of promoting the phagocytosis of $S$. pneumoniae type 14 . Conjugates that did not evoke specific antibodies against polysaccharide type 14 also did not display phagocytic capacity [73]. 


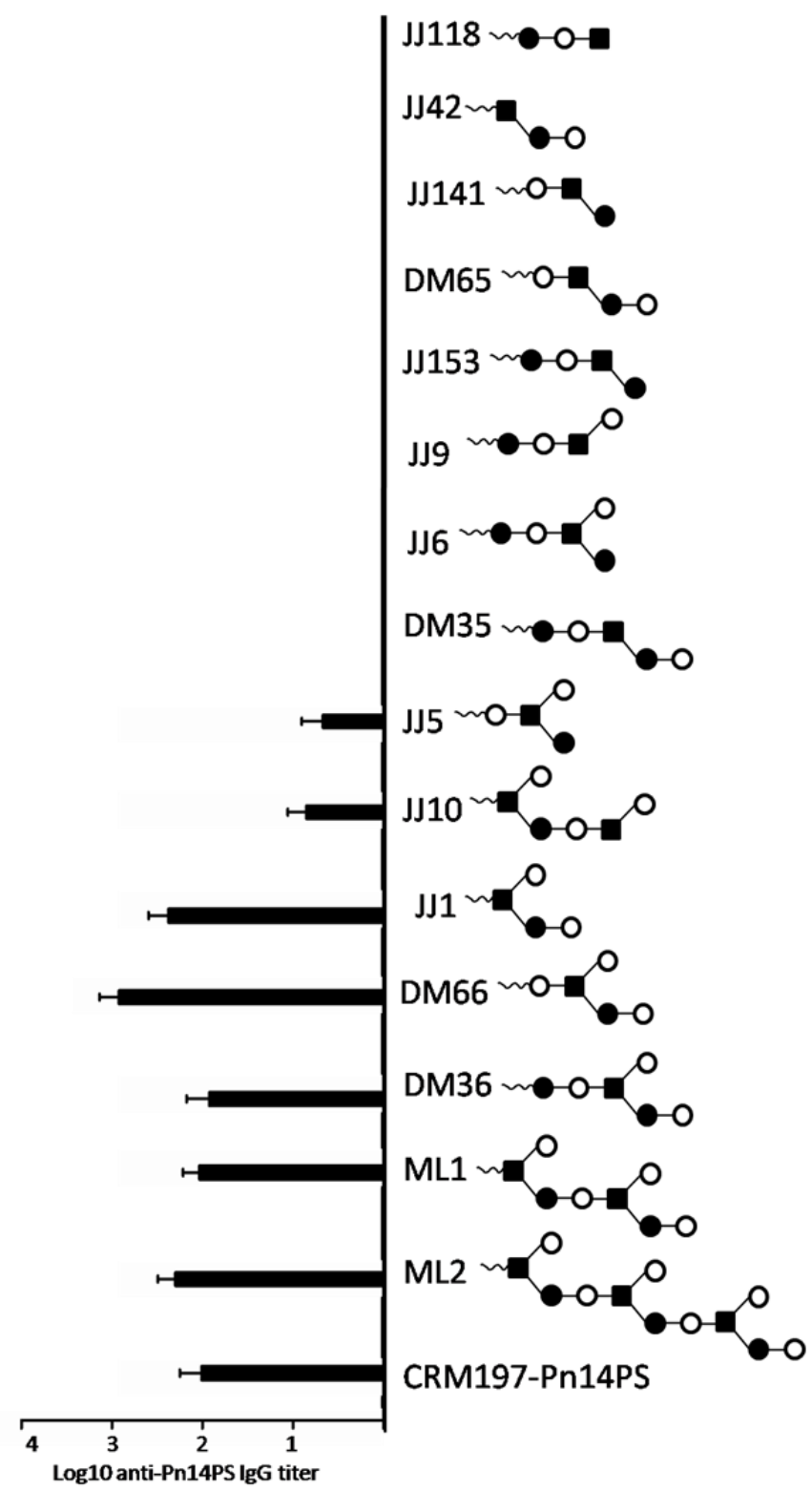

Figure 4. Level of anti-Pn14PS antibodies and schematic structure of overlapping synthetic oligosaccharide fragments of Pn14PS (Adopted from Safari et al 2008 [73]). The oligosaccharides were conjugated to $\mathrm{CRM}_{197}$ protein and the immunogenicity of those conjugates were studies in a mouse model. Mice were immunized with polysaccharide type 14 conjugated to CRM197 (CRM197-Pn14PS) as a positive control. Enzyme-linked immunosorbent assay was employed to measure specific anti-Pn14PS IgG antibodies after the booster immunization. Antibody titers were expressed as the $\log 10$ of the dilution Filled circle $=$ glucose $(\mathrm{Glc})$; open circle $=$ galactose $(\mathrm{Gal})$, and filled square $=\mathrm{N}$-acetylglucosamine $(\mathrm{GlcNAc})$. 
In conclusion, the present study has shown that the branched trisaccharide Glc-(Gal-)GlcNAc is the core structure inducing Pn14PS-specific antibodies and that the neighboring galactose at the non-reducing end significantly contributes to the induction of phagocytosispromoting antibodies [73]. Our study provides evidence that the branched tetrasaccharide Gal-Glc-(Gal-)GlcNAc is a prime candidate for a synthetic oligosaccharide conjugate vaccine against infections caused by S. pneumoniae type 14 [73].

\subsection{Relationship between polysaccharide of Pn14PS and GBSIII}

We also determined the minimal epitope in group B streptococcus type III polysaccharide (GBSIIIPS), using both a panel of anti-Pn14PS mouse sera and sera of humans vaccinated with either Pn14PS or GBSIIIPS as reported by Safari et al [80]. Native Pn14PS is structurally related to and has cross-reactivity with GBSIIIPS [81]. The branched structures of Pn14PS and GBSIIIPS differ only in the absence (in Pn14PS) or presence (in GBSIIIPS) of the $(\alpha 2 \rightarrow 3)$-linked sialic acid N-acetylneuraminic acid (Neu5Ac) in their side chains: $\{\rightarrow 4)-\beta-\mathrm{D}-\mathrm{Glcp}-(1 \rightarrow 6)-[ \pm \alpha-$ Neu5Ac- $(2 \rightarrow 3)-\beta$-D-Galp-( $1 \rightarrow 4)-] \beta-D-G l c p N A c-(1 \rightarrow 3)-\beta-D-G a l p-(1 \rightarrow\} n$ [82]. We reported that type-specific Pn14PS antibodies which recognize the branched structure of Pn14PS have a low affinity for the native GBSIIIPS and do not promote opsonophagocytosis of GBSIII, however desialylation of GBSIIIPS, however, resulted in dramatically higher affinity of anti-Pn14PS antibodies in mice when GBSIIIP was treated by nurimindase (desialylation) [80]. These results revealed that GBSIII bacteria are protected from binding of antibodies against Pn14PS by a residue of $(\alpha 2 \rightarrow 3)$-linked sialic acid, as described previously [83, 84].

\subsection{Booster immunization either with either neoglycoconjugate or native polysaccharide}

We investigated further the immune response to a neoglycoconjugate of Pn14PS (GC) on the outcome of sustained immunity to $S$. pneumoniae type 14 in a mouse model after the booster injection with either (GC) or native Pn14PS (PS) [85]. We found, as we expected, that the amount of specific IgG antibodies against Pn14PS increased substantially when a GC booster was given to mice previously primed with the same GC [85]. The induced antibodies were capable to opsonise S. pneumoniae type 14. Boosting with PS following a primary conjugate vaccine injection did not result in IgG antibody formation to Pn14PS (Table 1).

In order to explain these phenomena we investigated how a booster immunization with a GC or PS affects the cell-mediated immune response by measuring the production profile of a panel of cytokines [85]. We observed a high level of IL-5 in serum after a booster injection with GC (GC-GC or GC-GC-GC). Boosting with PS did not result in the induction of IL-5 nor of any of the other tested cytokines (Table 1; GC-PS and GC-PS-PS). We conclude that induction of the cytokine IL- 5 in serum is an early sign of a successful booster immunization and is a prerequisite for the production of specific anti-polysaccharide IgG antibodies [85]. In-vitro spleen cell cultures were also used to investigate the effect of a booster injection on activation of memory T cells. IL- 5 which well known Th2 cytokines, were evoked by the GC in spleen cell cultures of mice previously primed and boosted with the same GC [85]. In 
conclusion, the inability of polysaccharide to boost primed mice might be due to the incapability to induce the cytokines.

\begin{tabular}{|c|c|c|c|}
\hline \multirow{2}{*}{ Immunization $^{1}$} & \multirow{2}{*}{$\begin{array}{l}\text { IgG titer } \\
\left(\log _{10}\right)^{2}\end{array}$} & \multicolumn{2}{|c|}{ Level of Cytokine IL-5 (pg/ml) } \\
\hline & & In serum $^{3}$ & After stimulation $^{4}$ \\
\hline GC-GC & $2.18 \pm 0.22$ & $1022.3 \pm 275.2$ & $571.2 \pm 20.0$ \\
\hline GC-PS & $0.34 \pm 0.47$ & $0.3 \pm 0.5$ & $66.1 \pm 0.4$ \\
\hline GC-GC-GC & $3.02 \pm 0.17$ & $2700.4 \pm 112.3$ & $1172.8 \pm 7.1$ \\
\hline GC-PS-PS & 0.0 & 0.0 & $664.9 \pm 221$ \\
\hline Saline & 0.0 & $6.9 \pm 1.1$ & 0.0 \\
\hline
\end{tabular}

${ }^{1}$ Five mice per group were immunized with a CRM-neoglycoconjugate (GC), a synthetic branched tetrasaccharide of Pn14PS that is conjugated to a CRM197 protein. Booster doses containing either a GC (GC-GC and GC-GC-GC) or a native polysaccharide of Pn14PS (PS) (GC-PS, GCGC-PS, and GC-PS-PS) were injected at Weeks 5 and 10.

${ }^{2}$ ELISA was employed to measure specific anti-Pn14PS IgG antibodies, and expressed as the log10 of the sera dilution ${ }^{3}$ Cytokine levels in sera from mice receiving booster injection. Sera were collected on Day 1 after the primary immunization ${ }^{4}$ Splenocytes were isolated 7 days after the first booster injection. Spleen cells were cultured in vitro and stimulated with CRM-neoglycoconjugate and supernatants were collected $72 \mathrm{~h}$ after culture initiation.

Table 1. Effect of booster immunization either with with either the same neoglycoconjugate or a native polysaccharide (Adopted from Safari, D. el at [85] with permission)

\subsection{Improvement of anti-Pn14PS antibodies level by coadjuvant administration}

The immunogenicity of neoglycoconjugate was increased with adjuvant coadministration $[73,86]$. We set out to investigate in a mouse model the effect of adjuvant coadministration i.e. Quil-A, MPL, DDA, CpG and Alum on both the antibody- and cell-mediated immune response against a neoglycoconjugate as reported by Safari et al [87]. In the absence of adjuvant, immunization with neoglycoconjugate leads after a booster merely to IgG1 antibodies against PnP14PS. Coadministration of adjuvant had multiple effects: a diversified anti-Pn14PS IgG antibody response (also other IgG subclasses than IgG1 were evoked), an enhanced avidity and increased opsonic activity of these antibodies [87]. We found that next to Quil-A also DDA as a single dose or in combination with CpG had similar effects on the diversification of eliciting a broader variety of anti-Pn14PS IgG antibody subclasses. Meanwhile, CpG or alum on their own showed in majority IgG1 antibodies after booster immunization in a same pattern as in non adjuvant groups [87]. Compared to other adjuvants, codelivered Quil-A strongly improved the antibody avidity and enhanced the phagocytosis of S. pneumoniae type 14 [87].

\section{Future researches}

In this review, synthetic oligosaccharide-protein conjugates are proven to be effective vaccines in mice model. A logical next step would be a feasibility and immunogenicity study in human volunteers. Before that, a study should be started with synthetic oligosaccharide-protein conjugates for at least the pneumococcal serotypes 1, 4, 5, 9V and 18C and should even have been completed, because the minimal epitopes for these polysaccharides are still unknown. 
To improve the immunogenicity of oligosaccharide-protein conjugates co-delivery of adjuvants are required. As an alternative to the addition of adjuvants, studies should be initiated to direct oligosaccharide-protein conjugates to dendritic cells by incorporation of specific ligands. Targeting to and activation of dendritic cells by TLR5 is a possibility to be explored.

\section{Author details}

Dodi Safari*

Eijkman Institute for Molecular Biology, Jakarta, Indonesia

Ger Rijkers

Department of Sciences, Roosevelt Academy, Middelburg and Department of Medical Microbiology and Immunology, St. Antonius Hospital, Nieuwegein, The Netherlands

Harm Snippe

Department of Medical Microbiology, University Medical Center Utrecht, Utrecht, The Netherlands

\section{Acknowledgement}

This review is a part of the PhD thesis of Dodi Safari with the title: Development of new synthetic oligosaccharide vaccines: the immunogenicity of oligosaccharide- CRM 197 neoconjugates and oligosaccharide/peptide hybrid gold nanoparticles based on the capsular polysaccharide structure of Streptococcus pneumoniae type. 14. Utrecht University. 2010. This work was supported by a grant from the European Commission under Contract No: MRTNCT-2004-005645.

\section{References}

[1] Landsteiner K, Jacobs J. Studies on the sensitization of animals with simple chemical compounds. J.Exp.Med. 1935;61:643-56.

[2] Mitchison NA; Rajewsky K; Taylor RB. Sterzl J and Riha I, editors.Prague symposium on developmental aspects of antibody formation and structure. Praha: Academia Publishing House; 1970.

[3] Goebel WF. Studies on antibacterial immunity induced by artificial antigens. I. Immunity to experimental pneumococcal infection with an antigen containing cellobiuronic acid. J.Exp.Med. 1939;69:353-64.

[4] Goebel WF. Studies on antibacterial immunity induced by artificial antigens. II. Immunity to experimental pneumococcal infection with antigens containing saccharides of synthetic origin. J.Exp.Med. 1940;72:33-48.

[5] Campbell JH, Pappenheimer AM. Quantitative studies of the specificity of antipneumococcal polysaccharide antibodies, type III and VIII. I. Isolation of

${ }^{*}$ Corresponding Author 
oligosaccharides from acid and from enzymatic hydrolysates. Immunochemistry 1966;3:195-212.

[6] Mage RG, Kabat EA. Immunochemical studies on dextrans: III. The specificities of rabbit antidextrans. Further findings on antidextrans with 1,2- and 1,6-specificities. J.Immunol. 1963;(91):633-40.

[7] Kabat EA; Mayer MM. Experimental immunochemistry. IL, USA: Springfield; 1948.

[8] Snippe H, van Dam JEG, van Houte AJ, Willers JMN, Kamerling JP, Vliegenthart JFG. Preparation of a semisynthetic vaccine to Streptococcus pneumoniae type 3. Infect.Immun. 1983;42(2):842-4.

[9] Verez-Bencomo V, Fernandez-Santana V, Hardy E, Toledo ME, Rodriguez A, Baly A, Harrera L, Izquierdo M, Villar A, Valdes Y, Cosme K, Deler ML, Montane M, Gracia E, Ramos A, Aguilar A, Medina E, Torano G, Sosa I, Hernandez I, Martinez R, Muzachio A, Carmenates A, Costa L, Cardoso F, Campa C, Diaz V, Roy R. A synthetic conjugate polysaccharide vaccine against Haemophilus influenzae type b. Science 2004;305:522-5.

[10] Safari D, Maradi M, Chiodo F, Dekker HA, Shan Y, Adamo R, Oscarson S, Rijkers GT, Lahmann M, Kamerling JP, Penades S, Snippe H. Gold nanoparticles as carriers for a synthetic Streptococcus pneumoniae type 14 conjugate vaccine. Nanomedicine 2012;doi:10.2217/NNM.11.151

[11] Bryce J, Boschi-Pinto C, Shibuya K, Black RE. WHO estimates of the causes of death in children. Lancet 2005;365(9465):1147-52.

[12] World Health Organization. Pneumococcal conjugate vaccine for childhood immunization--WHO position paper. Wkly.Epidemiol.Rec. 2007;82(12):93-104.

[13] Kadioglu A, Weiser JN, Paton JC, Andrew PW. The role of Streptococcus pneumoniae virulence factors in host respiratory colonization and disease. Nat.Rev.Microbiol 2008;6(4):288-301.

[14] de Velasco EA, Verheul AF, Verhoef J, Snippe H. Streptococcus pneumoniae: virulence factors, pathogenesis, and vaccines. Microbiol.Rev. 1995;59(4):591-603.

[15] van der PT, Opal SM. Pathogenesis, treatment, and prevention of pneumococcal pneumonia. Lancet 2009;374(9700):1543-56.

[16] Kamerling JP. Tomasz A, editors. Streptococcus pneumoniae, molecular biology \& mechanisms of disease. New York: Mary Ann Liebert; 1999;Pneumococcal polysaccharides: A chemical view. p. 81-114.

[17] Park IH, Pritchard DG, Cartee R, Brandao A, Brandileone MC, Nahm MH. Discovery of a new capsular serotype (6C) within serogroup 6 of Streptococcus pneumoniae. J Clin.Microbiol 2007;45(4):1225-33.

[18] Bratcher PE, Kim KH, Kang JH, Hong JY, Nahm MH. Identification of natural pneumococcal isolates expressing serotype $6 \mathrm{D}$ by genetic, biochemical and serological characterization. Microbiology 2010;156:555-60.

[19] Oftadeh S, Satzke C, Gilbert GL. Identification of the newly described Streptococcus pneumoniae serotype 6D using Quellung reaction and PCR. J Clin.Microbiol 2010;

[20] Calix JJ, Nahm MH. A new pneumococcal serotype, 11E, has a variably inactivated wcjE gene. J Infect.Dis. 2010;202(1):29-38. 
[21] Bentley SD, Aanensen DM, Mavroidi A, Saunders D, Rabbinowitsch E, Collins M, Donohoe K, Harris D, Murphy L, Quail MA, Samuel G, Skovsted IC, Kaltoft MS, Barrell B, Reeves PR, Parkhill J, Spratt BG. Genetic analysis of the capsular biosynthetic locus from all 90 pneumococcal serotypes. PLoS.Genet. 2006;2(3):e31

[22] Mavroidi A, Aanensen DM, Godoy D, Skovsted IC, Kaltoft MS, Reeves PR, Bentley SD, Spratt BG. Genetic relatedness of the Streptococcus pneumoniae capsular biosynthetic loci. J.Bacteriol. 2007;189(21):7841-55.

[23] Llull D, Garcia E, Lopez R. Tts, a processive beta-glucosyltransferase of Streptococcus pneumoniae, directs the synthesis of the branched type 37 capsular polysaccharide in Pneumococcus and other gram-positive species. J Biol.Chem 2001;276(24):21053-61.

[24] Arrecubieta C, Lopez R, Garcia E. Type 3-specific synthase of Streptococcus pneumoniae (Cap3B) directs type 3 polysaccharide biosynthesis in Escherichia coli and in pneumococcal strains of different serotypes. J Exp.Med 1996;184(2):449-55.

[25] Breukels MA, Rijkers GT, Voorhorst-Ogink MM, Zegers BJ, Sanders LA. Pneumococcal conjugate vaccine primes for polysaccharide-inducible IgG2 antibody response in children with recurrent otitis media acuta. J.Infect.Dis. 1999;179(5):1152-6.

[26] Rennels MB, Edwards KM, Keyserling HL, Reisinger KS, Hogerman DA, Madore DV, Chang I, Paradiso PR, Malinoski FJ, Kimura A. Safety and immunogenicity of heptavalent pneumococcal vaccine conjugated to $\mathrm{CRM}_{197}$ in United States infants. Pediatrics 1998;101(4 Pt 1):604-11.

[27] Prymula R, Kriz P, Kaliskova E, Pascal T, Poolman J, Schuerman L. Effect of vaccination with pneumococcal capsular polysaccharides conjugated to Haemophilus influenzaederived protein D on nasopharyngeal carriage of Streptococcus pneumoniae and $H$. influenzae in children under 2 years of age. Vaccine 2009;28(1):71-8.

[28] French N. Use of pneumococcal polysaccharide vaccines: no simple answers. J.Infect. 2003;46(2):78-86.

[29] Ada G, Isaacs D. Carbohydrate-protein conjugate vaccines. Clin.Microbiol.Infect. 2003;9(2):79-85.

[30] Kalka-Moll WM, Tzianabos AO, Bryant PW, Niemeyer M, Ploegh HL, Kasper DL. Zwitterionic polysaccharides stimulate T cells by MHC class II-dependent interactions. J Immunol. 2002;169(11):6149-53.

[31] Choi YH, Roehrl MH, Kasper DL, Wang JY. A unique structural pattern shared by Tcell-activating and abscess-regulating zwitterionic polysaccharides. Biochemistry 2002;41(51):15144-51.

[32] Karnezis TT, Smith A, Whittier S, Haddad J, Saiman L. Antimicrobial resistance among isolates causing invasive pneumococcal disease before and after licensure of heptavalent conjugate pneumococcal vaccine. PLoS One. 2009;4(6):e5965

[33] Valenzuela MT, de Quadros C. Antibiotic resistance in Latin America: a cause for alarm. Vaccine 2009;27 Suppl 3:C25-C28

[34] Vlieghe E, Phoba MF, Tamfun JJ, Jacobs J. Antibiotic resistance among bacterial pathogens in Central Africa: a review of the published literature between 1955 and 2008. Int.J Antimicrob.Agents 2009;34(4):295-303. 
[35] Siira L, Rantala M, Jalava J, Hakanen AJ, Huovinen P, Kaijalainen T, Lyytikainen O, Virolainen A. Temporal trends of antimicrobial resistance and clonality of invasive Streptococcus pneumoniae isolates in Finland, 2002 to 2006. Antimicrob.Agents Chemother. 2009;53(5):2066-73.

[36] Vila-Corcoles A, Bejarano-Romero F, Salsench E, Ochoa-Gondar O, de DC, GomezBertomeu F, Raga-Luria X, Cliville-Guasch X, Arija V. Drug-resistance in Streptococcus pneumoniae isolates among Spanish middle aged and older adults with communityacquired pneumonia. BMC.Infect.Dis. 2009;9:36

[37] Imai S, Ito Y, Ishida T, Hirai T, Ito I, Maekawa K, Takakura S, Iinuma Y, Ichiyama S, Mishima M. High prevalence of multidrug-resistant Pneumococcal molecular epidemiology network clones among Streptococcus pneumoniae isolates from adult patients with community-acquired pneumonia in Japan. Clin.Microbiol.Infect. 2009;

[38] Shibl AM. Distribution of serotypes and antibiotic resistance of invasive pneumococcal disease isolates among children aged 5 years and under in Saudi Arabia (2000-2004). Clin.Microbiol.Infect. 2008;14(9):876-9.

[39] Yang F, Xu XG, Yang MJ, Zhang YY, Klugman KP, McGee L. Antimicrobial susceptibility and molecular epidemiology of Streptococcus pneumoniae isolated from Shanghai, China. Int.J.Antimicrob.Agents 2008;32(5):386-91.

[40] Gottlieb T, Collignon PJ, Robson JM, Pearson JC, Bell JM. Prevalence of antimicrobial resistances in Streptococcus pneumoniae in Australia, 2005: report from the Australian Group on Antimicrobial Resistance. Commun.Dis.Intell. 2008;32(2):242-9.

[41] Barocchi MA, Censini S, Rappuoli R. Vaccines in the era of genomics: the pneumococcal challenge. Vaccine 2007;25(16):2963-73.

[42] O'Brien KL, Hochman M, Goldblatt D. Combined schedules of pneumococcal conjugate and polysaccharide vaccines: is hyporesponsiveness an issue? Lancet Infect.Dis. 2007;7(9):597-606.

[43] Singleton RJ, Hennessy TW, Bulkow LR, Hammitt LL, Zulz T, Hurlburt DA, Butler JC, Rudolph K, Parkinson A. Invasive pneumococcal disease caused by nonvaccine serotypes among alaska native children with high levels of 7-valent pneumococcal conjugate vaccine coverage. JAMA 2007;297(16):1784-92.

[44] Douglas RM, Paton JC, Duncan SJ, Hansman DJ. Antibody response to pneumococcal vaccination in children younger than five years of age. J Infect.Dis. 1983;148(1):131-7.

[45] Ortqvist A, Hedlund J, Burman LA, Elbel E, Hofer M, Leinonen M, Lindblad I, Sundelof B, Kalin M. Randomised trial of 23-valent pneumococcal capsular polysaccharide vaccine in prevention of pneumonia in middle-aged and elderly people. Swedish Pneumococcal Vaccination Study Group. Lancet 1998;351(9100):399-403.

[46] Teshale EH, Hanson D, Flannery B, Phares C, Wolfe M, Schuchat A, Sullivan P. Effectiveness of 23-valent polysaccharide pneumococcal vaccine on pneumonia in HIVinfected adults in the United States, 1998--2003. Vaccine 2008;26(46):5830-4.

[47] Veras MA, Enanoria WT, Castilho EA, Reingold AL. Effectiveness of the polysaccharide pneumococcal vaccine among HIV-infected persons in Brazil: a case control study. BMC.Infect.Dis. 2007;7:119 
[48] Whitney CG, Farley MM, Hadler J, Harrison LH, Bennett NM, Lynfield R, Reingold A, Cieslak PR, Pilishvili T, Jackson D, Facklam RR, Jorgensen JH, Schuchat A. Decline in invasive pneumococcal disease after the introduction of protein-polysaccharide conjugate vaccine. N.Engl.J.Med. 2003;348(18):1737-46.

[49] Pavia M, Bianco A, Nobile CG, Marinelli P, Angelillo IF. Efficacy of pneumococcal vaccination in children younger than 24 months: a meta-analysis. Pediatrics 2009;123(6):e1103-e1110

[50] Isaacman DJ, McIntosh ED, Reinert RR. Burden of invasive pneumococcal disease and serotype distribution among Streptococcus pneumoniae isolates in young children in Europe: impact of the 7-valent pneumococcal conjugate vaccine and considerations for future conjugate vaccines. Int.J.Infect.Dis. 2009;14(3):e197-209.

[51] Knuf M, Szenborn L, Moro M, Petit C, Bermal N, Bernard L, Dieussaert I, Schuerman L. Immunogenicity of routinely used childhood vaccines when coadministered with the 10 -valent pneumococcal non-typeable Haemophilus influenzae protein D conjugate vaccine (PHiD-CV). Pediatr.Infect.Dis.J. 2009;28(4 Suppl):S97-S108

[52] Bermal N, Szenborn L, Chrobot A, Alberto E, Lommel P, Gatchalian S, Dieussaert I, Schuerman L. The 10-valent pneumococcal non-typeable Haemophilus influenzae protein D conjugate vaccine (PHiD-CV) coadministered with DTPw-HBV/Hib and poliovirus vaccines: assessment of immunogenicity. Pediatr.Infect.Dis.J. 2009;28(4 Suppl):S89-S96

[53] Meng C, Lin H, Huang J, Wang H, Cai Q, Fang L, Guo Y. Development of 5-valent conjugate pneumococcal protein A - Capsular polysaccharide pneumococcal vaccine against invasive pneumococcal disease. Microb.Pathog. 2009;47(3):151-6.

[54] Bogaert D, de Groot R, Hermans PWM. Streptococcus pneumoniae colonisation: the key to pneumococcal disease . Lancet.Infect.Dis. 2004;4:144-54.

[55] Xin W, Li Y, Mo H, Roland KL, Curtiss R, III. PspA family fusion proteins delivered by attenuated Salmonella enterica serovar Typhimurium extend and enhance protection against Streptococcus pneumoniae. Infect.Immun. 2009;77(10):4518-28.

[56] Francis JP, Richmond PC, Pomat WS, Michael A, Keno H, Phuanukoonnon S, Nelson JB, Whinnen M, Heinrich T, Smith WA, Prescott SL, Holt PG, Siba PM, Lehmann D, van den Biggelaar AH. Maternal antibodies to pneumolysin, but not pneumococcal surface protein A, delay early pneumococcal carriage in high-risk Papua New Guinean infants. Clin.Vaccine Immunol. 2009;16(11):1633-8.

[57] Ljutic B, Ochs M, Messham B, Ming M, Dookie A, Harper K, Ausar SF. Formulation, stability and immunogenicity of a trivalent pneumococcal protein vaccine formulated with aluminum salt adjuvants. Vaccine 2012;Epub ahead of print

[58] Pozsgay V. Recent developments in synthetic oligosaccharide-based bacterial vaccines. Curr.Top.Med Chem 2008;8(2):126-40.

[59] Jansen WT, Snippe H. Short-chain oligosaccharide protein conjugates as experimental pneumococcal vaccines. Indian.J.Med.Res. 2004;119:7-12.

[60] Benaissa-Trouw B, Lefeber DJ, Kamerling JP, Vliegenthart JF, Kraaijeveld K, Snippe H. Synthetic polysaccharide type 3-related di-, tri-, and tetrasaccharide- $\mathrm{CRM}_{197}$ conjugates 
induce protection against Streptococcus pneumoniae type 3 in mice. Infect.Immun. 2001;69(7):4698-701.

[61] Plante OJ, Palmacci ER, Seeberger PH. Automated solid-phase synthesis of oligosaccharides. Science 2001;291(5508):1523-7.

[62] Saksena R, Ma X, Wade TK, Kovác P, Wade WF. Length of the linker and the interval between immunizations influences the efficacy of Vibrio cholerae O1,Ogawa hexasaccharide neoglycoconjugates. FEMS Immunol.Med.Microbiol. 2006;47:116-28.

[63] Saksena R, Ma X, Wade TK, Kovac P, Wade WF. Effect of saccharide length on the immunogenicity of neoglycoconjugates from synthetic fragments of the O-SP of Vibrio cholerae O1, serotype Ogawa. Carbohydr.Res. 2005;340:2256-69.

[64] Bongat AF, Saksena R, Adamo R, Fujimoto Y, Shiokawa Z, Peterson DC, Fukase K, Vann WF, Kovac P. Multimeric bivalent immunogens from recombinant tetanus toxin $\mathrm{H}(\mathrm{C})$ fragment, synthetic hexasaccharides, and a glycopeptide adjuvant. Glycoconj.J. 2009;27(1):69-77.

[65] Phalipon A, Tanguy M, Grandjean C, Guerreiro C, Belot F, Cohen D, Sansonetti PJ, Mulard LA. A synthetic carbohydrate-protein conjugate vaccine candidate against Shigella flexneri 2a infection. J.Immunol. 2009;182(4):2241-7.

[66] Said HF, Phalipon A, Tanguy M, Guerreiro C, Belot F, Frisch B, Mulard LA, Schuber F. Rational design and immunogenicity of liposome-based diepitope constructs: application to synthetic oligosaccharides mimicking the Shigella flexneri 2a O-antigen. Vaccine 2009;27(39):5419-26.

[67] Schofield L, Hewitt MC, Evans K, Siomos MA, Seeberger PH. Synthetic GPI as a candidate anti-toxic vaccine in a model of malaria. Nature 2002;418(6899):785-9.

[68] Jeon I, Lee D, Krauss IJ, Danishefsky SJ. A new model for the presentation of tumorassociated antigens and the quest for an anticancer vaccine: a solution to the synthesis challenge via ring-closing metathesis. J.Am.Chem.Soc. 2009;131(40):14337-44.

[69] de Velasco EA, Verheul AF, Veeneman GH, Gomes LJ, van Boom JH, Verhoef J, Snippe $\mathrm{H}$. Protein-conjugated synthetic di- and trisaccharides of pneumococcal type 17F exhibit a different immunogenicity and antigenicity than tetrasaccharide. Vaccine 1993;11(14):1429-36.

[70] Jansen WT, Verheul AFM, Veeneman GH, van Boom JH, Snippe H. Revised interpretation of the immunological results obtained with pneumococcal polysaccharide 17F derived synthetic di-, tri- and tetrasaccharide conjugates in mice and rabbits. Vaccine 2002;20:19-21.

[71] de Velasco EA, Verheul AF, van Steijn AM, Dekker HA, Feldman RG, Fernandez IM, Kamerling JP, Vliegenthart JF, Verhoef J, Snippe H. Epitope specificity of rabbit immunoglobulin $\mathrm{G}$ ( $\mathrm{IgG}$ ) elicited by pneumococcal type $23 \mathrm{~F}$ synthetic oligosaccharideand native polysaccharide-protein conjugate vaccines: comparison with human antipolysaccharide 23F IgG. Infect.Immun. 1994;62(3):799-808.

[72] Jansen WT, Hogenboom S, Thijssen MJL, Kamerling JP, Vliegenthart JFG, Verhoef J, Snippe H, Verheul AFM. Synthetic 6B di-, tri-, and tetrasaccharide-protein conjugates contain pneumococcal type $6 \mathrm{~A}$ and $6 \mathrm{~B}$ common and 6B-specific epitopes that elicit protective antibodies in mice. Infect.Immun. 2001;69(2):787-93. 
[73] Safari D, Dekker HA, Joosten JA, Michalik D, de Souza AC, Adamo R, Lahmann M, Sundgren A, Oscarson S, Kamerling JP, Snippe H. Identification of the smallest structure capable of evoking opsonophagocytic antibodies against Streptococcus pneumoniae type 14. Infect.Immun. 2008;76(10):4615-23.

[74] Mawas F, Niggemann J, Jones C, Corbel MJ, Kamerling JP, Vliegenthart JFG. Immunogenicity in a mouse model of a conjugate vaccine made with a synthetic single repeating unit of type 14 pneumococcal polysaccharide coupled to CRM197. Infect.Immun. 2002;70(9):5107-14.

[75] Lindberg B, Lonngren J, Powel DA. Structural studies on the specific type 14 pneumococcal polysaccharide. Carbohydr.Res. 1977;58:177-86.

[76] Joosten JA, Lazet BJ, Kamerling JP, Vliegenthart JF. Chemo-enzymatic synthesis of tetra, penta-, and hexasaccharide fragments of the capsular polysaccharide of Streptococcus pneumoniae type 14. Carbohydr.Res 2003;338(23):2629-51.

[77] Joosten JA, Kamerling JP, Vliegenthart JF. Chemo-enzymatic synthesis of a tetra- and octasaccharide fragment of the capsular polysaccharide of Streptococcus pneumoniae type 14. Carbohydr.Res 2003;338(23):2611-27.

[78] Michalik D, Vliegenthart JFG, Kamerling JP. Chemoenzymic synthesis of oligosaccharide fragments of the capsular polysaccharide of Streptococcus pneumoniae type 14. J.Chem.Soc., Perkin Trans.1 2002;1973-81.

[79] Sundgren A, Lahmann M, Oscarson S. Block synthesis of Streptococcus pneumoniae type 14 capsular polysaccharide structures. J.Carbohydr.Chem. 2005;24(4):379-91.

[80] Safari D, Dekker HA, Rijkers G, van der Ende A, Kamerling JP, Snippe H. The immune response to group B streptococcus type III capsular polysaccharide is directed to the Glc-GlcNAc-Gal- backbone epitope. Glycoconj.J. 2011;28:557-67.

[81] Guttormsen HK, Baker CJ, Nahm MH, Paoletti LC, Zughaier SM, Edwards MS, Kasper DL. Type III group B streptococcal polysaccharide induces antibodies that cross-react with Streptococcus pneumoniae type 14. Infect.Immun. 2002;70(4):1724-38.

[82] Kadirvelraj R, Gonzalez-Quteirino J, Foley BL, Beckham ML, Jennings HJ, Foote S, Ford MG, Woods RJ. Understanding the bacterial polysaccharide antigenicity of Streptococcus agalactiae versus Streptococcus pneumoniae. Proc.Natl.Acad.Sci.USA 2007;103(21):8149-54.

[83] Jennings HJ, Lugowski C, Kasper DL. Conformational aspects critical to the immunospecificity of the type III group B streptococcal polysaccharide. Biochemistry 1981;20(16):4511-8.

[84] Miernyk KM, Butler JC, Bulkow LR, Singleton RJ, Hennessy TW, Dentinger CM, Peters HV, Knutsen B, Hickel J, Parkinson AJ. Immunogenicity and reactogenicity of pneumococcal polysaccharide and conjugate vaccines in alaska native adults 55-70 years of age. Clin.Infect.Dis. 2009;49(2):241-8.

[85] Safari D, Dekker HA, de Jong B, Rijkers G, Kamerling JP, Snippe H. Antibody- and cellmediated immune responses to a synthetic oligosaccharide conjugate vaccine after booster immunization. Vaccine 2011;29(38):6498-504.

[86] Lefeber DJ, Benaissa-Trouw B, Vliegenthart JFG, Kamerling JP, Jansen WTM, Kraaijeveld K, Snippe H. Th1-directing adjuvants increase the immunogenicity of 
634 The Complex World of Polysaccharides

oligosaccharide-protein conjugate vaccines related to Streptococcus pneumoniae type 3. Infect.Immun. 2003;71(12):6915-20.

[87] Safari D, Dekker HA, Rijkers G, Snippe H. Codelivery of adjuvants at the primary immunization site is essential for evoking a robust immune response to neoglycoconjugates. Vaccine 2011;29(4):849-54. 